\title{
Business Analytics: Yes, we can!
}

\section{Liebe Leserinnen und Leser,}

Controller sind im Unternehmen die Experten für die Analyse von Small Data - überschaubaren Mengen unternehmensinterner finanzieller Daten. Hingegen fremdeln die meisten von ihnen trotz aller Lippenbekenntnisse bereits, wenn sich nicht-finanzielle Kennzahlen den Gesetzmäßigkeiten der Analyse vertrauter interner Finanzkennzahlen ganz oder teilweise entziehen. Schon das macht deutlich, wie groß die aktuelle Herausforderung durch Business Analytics ist, wo es (im Idealfall) um die Analyse großer Mengen sich ständig verändernder, interner und externer, finanzieller und nichtfinanzieller, historischer und aktueller, strukturierter und nicht-strukturierter Daten geht. Eine solche Analyse erfordert ein solides Verständnis statistischer Methoden (auch jenseits der Regressionsanalyse), das den meisten Controllern weitgehend fehlt. Ganz im Gegensatz zu den Mathematikern, Physikern und eigens ausgebildeten Data Analysts in sogenannten Data-Science-Teams, die in großen Unternehmen zunehmend für die Analyse von Big Data verantwortlich zeichnen! Doch damit nicht genug. Parallel zu dieser Entwicklung wird die Analyse von unternehmensbezogenen Small Data zunehmend zur Commodity. Zumindest in großen Unternehmen sind Manager heute im Regelfall besser ausgebildet und bringen mehr Handwerkszeug mit als noch vor ein oder zwei Jahrzehnten. Und genau diese Manager werden durch die Fortschritte der Informationstechnologie auch zunehmend technisch in die Lage versetzt, gängige Small-Data-basierte Analysen selbst vorzunehmen.

Controller müssen sich diesen Herausforderungen endlich stellen. Das heißt zunächst, die Toolbox und die damit verbundenen Fähigkeiten zu erweitern. Controller müssen in den Feldern Statistik und Programmierung eine ehrliche Bestandsaufnahme machen: Was können wir? Und was nicht (wirklich)? Auf dieser Basis gilt es, die Abweichung vom Soll zu beseitigen. In der Regel wird dies durch eine Kombination aus der Qualifizierung vorhandener und der Einstellung entsprechend qualifizierter neuer Controller erfolgen. Daneben muss die Verantwortung für Business Analytics klar geregelt sein: Soll die Analyse von Big Data zentral oder dezentral erfolgen,

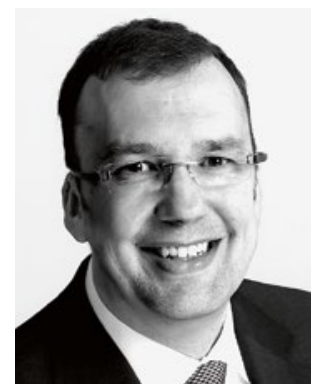

Utz Schäffer

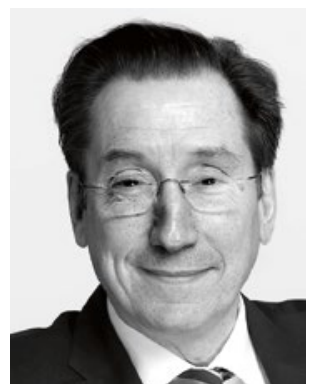

Jürgen Weber soll sie im Controlling oder anderswo angesiedelt sein? Was macht aus der Perspektive des Controllings Sinn und was ist durchsetzbar? Auch wenn hier vielfach schon Tatsachen geschaffen sind und Controller oft eher außen vor sind.

Die Herausforderung hat aber noch eine zweite, weiter gefasste Dimension: Controller müssen mehr denn je für die Sicherstellung rationaler Entscheidungen im Unternehmen kämpfen! Das umfasst mehr als die Analyse von Daten im Hinterzimmer. Falsche Annahmen über das Geschäftsmodell oder die Tragfähigkeit der zugrunde liegenden Daten, kognitive Verzerrungen der Entscheider und blanker Opportunismus stehen rationalen Entscheidungen des Managements auch dann entgegen, wenn das analytische Potenzial der Unternehmung wächst. Entsprechend gilt es mehr denn je, eine Kultur des faktenbasierten, analytischen Entscheidens im Unternehmen voranzubringen und einen engen Nexus zwischen der Welt der Zahlen und dem operativen Geschäft sicherzustellen. Fürwahr keine leichte Aufgabe. Aber wer sollte sie übernehmen, wenn nicht Controller. Können wir das? Hoffentlich. Viel Spaß bei der Lektüre wünschen Ihnen
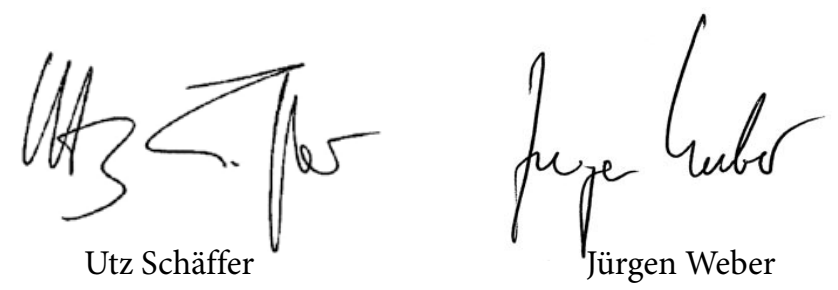